\title{
Caracterização dos Indicadores Geomorfológicos na Bacia Hidrográfica do Rio Verde, Ponta Grossa - PR
}

\section{Characterization of Geomorphological Indicators in the Green River Basin, Pon- ta Grossa - PR}

Karla Thais Barreto *

Maria Ligia Cassol Pinto **

\begin{abstract}
Resumo:
O presente artigo tem por objetivo caracterizar os indicadores geomorfológicos na bacia hidrográfica do rio Verde, localizada no município de Ponta Grossa, Campos Gerais do Paraná. Este rio faz parte da Bacia Sedimentar do Paraná, no setor afetado pelo Arco de Ponta Grossa, cujo relevo pode limitar os usos do solo, devido a presença de cânions. Foram realizados trabalhos de campo e interpretação de imagens orbitais para a obtenção dos índices de declividade, formas, orientação das vertentes e lineamentos estruturais. Os resultados apontaram que, a forma da bacia hidrográfica - sentido NE-SW, em parte pela drenagem encaixada nos lineamentos de mesma orientação ao Arco. As vertentes predominantes com formas convexas curtas, divergente-retilínea apresentando orientação N/NW, com declividades nas classes plano a suave ondulado. Tais características são reflexo da influência tectolitoestrutural, quanto condicionantes dos usos e da presença de processos erosivos.
\end{abstract}

\begin{abstract}
:
The present article aims to characterize the geomorphological indicators in the basin area of the Verde River, located in the city of Ponta Grossa, Campos Gerais of Paraná. This river is part of the Paraná Sedimentary Basin, in the area affected by the Ponta Grossa Arch, whose relief may limit land uses due to the presence of canyons. Fieldwork and interpretation of orbital images were performed to obtain slope indexes, shapes, orientation of the slopes and structural lineaments. The results pointed out that, in the form of the hydrographic basin - NE-SW direction, and in part by the drainage embedded in the lineaments of the same orientation to the Arch. The predominant slopes with short, divergent-rectilinear convex forms presenting N / NW orientation, with gradients in the flat to soft wavy classes. These characteristics are a reflection of the tecto-lithostructural influence, as conditioning factors of the uses and presence of erosive processes.
\end{abstract}

* Eng. Agrônoma. Mestre em Gestão do Território pela Universidade Estadual de Ponta Grossa (UEPG).

** Professora Doutora do Departamento de Geociências e do Programa de Pós-Graduação em Geografia da Universidade Estadual de Ponta Grossa (UEPG).

\section{Palavras-chave:}

Rede de Drenagem, Formas e Declividade

Controle Tectônico, Lineamentos Estruturais.

Key-Words:

Drainage Network, Shapes and Declivity, Tectonic Control, Structural Lineaments. 


\section{INTRODUÇÃO}

Os indicadores geomorfológicos são variáveis importantes nas análises ambientais aplicadas a bacias hidrográficas permitindo representar as formas do relevo e da rede de drenagem. Estes, segundo Guerra (2003) são de grande importância na compreensão dos processos erosivos. Se faz necessário conhecer a sua formação, constituição e dinâmica, pois os rios são agentes importantes no modelado do relevo terrestre, transportando sedimentos das vertentes.

Os processos erosivos são influenciados por várias características, tais como: litoestrutura, declividade, orientação, comprimento de rampa, formas das vertentes e uso do solo. Com isso, a dinâmica da paisagem torna-se complexa, intensificando, por exemplo, nas áreas de usos agropastoris, pois o solo fica mais exposto à ação dos processos erosivos, onde nos períodos mais chuvosos estabelece-se com mais intensidade, o aumento nas taxas de escoamento superficial, que são, em grande parte, responsáveis pela perda do solo nas áreas (CONACHER e DALRYMPLE, 1977).

Além disso, se as áreas de estudo apresentam fraturas ou falhas, os condicionantes litoestruturais influenciam na incidência de processos se o manejo das áreas não for adequado. Neste artigo, considera-se lineamento como uma feição linear, retilínea ou suavemente encurva$\mathrm{da}$, que pode ser tanto simples como composta. Os lineamentos podem refletir fenômenos de subsuperfície associados com o movimento diferencial de blocos de falhas (O'LEARY et al., 1976).

Nesta perspectiva, o objetivo deste artigo foi caracterizar os indicadores geomorfológicos na bacia hidrográfica do rio Verde, município de Ponta Grossa, PR.

Foram utilizados os dados geomorfométricos derivados de processamentos efetuados do Projeto Topodata, disponíveis no website do Instituto Nacional de Pesquisas Espaciais (INPE) para a obtenção das formas do terreno e as cartas topográficas da DSG para a geração dos mapas de declividade e hipsometria, sendo que, através destes dados possibilitou-se o cruzamento de mapas no formato raster através de álgebra de mapas para visualização de áreas mais propícias geomorfologicamente aos processos erosivos.

\section{METODOLOGIA}

1.1 A Bacia do Rio Verde - Município de Ponta Grossa - Área de estudo
Os Campos Gerais do Paraná definido por Maack (1948) apresentam uma paisagem geomorfológica desenvolvida nas condições litoestruturais da borda oriental da Bacia Sedimentar do Paraná, na Unidade Morfoescultural do Segundo Planalto do Paraná, e bioclimáticas que incluem a vegetação de Floresta Ombrófila Mista, cerrado e campo associados ao subtropical úmido controlado por massas de ar tropical e polar atlântica.

Nessa paisagem se encontra a bacia do Rio Verde nas Subunidades Morfoesculturais dos Planaltos de São Luiz do Purunã e Ponta Grossa (MINEROPAR, 2006), ocupando a porção nordeste do município de Ponta Grossa - Figura 01. Este, por sua vez, inserido na região Centro Oriental do Paraná (IPARDES, 2012).

A bacia do Rio Verde se encontra delimitada pelas coordenadas UTM 581672m/7226413m e $603729 \mathrm{~m} / 7220512 \mathrm{~m}$, setor NE da carta SG-22-X-C-II e a NW da SG- 22-X-C III.O rio Verde é afluente da margem esquerda do Rio Pitangui, que por sua vez é tributário do rio Tibagi (Sistema Pitangui-Tibagi-Paranapanema-Paraná). Sua paisagem pode ser caracterizada como rural-urbana com predomínio de usos agropecuário e urbano (MINEROPAR, 2005).

Segundo Cruz (2009), os afluentes do rio Verde cortam a área urbana de Ponta Grossa e merecem destaque, pois como em sua maioria são encaixados em vales que exercem um papel fundamental para o clima de Ponta Grossa. Neles, há uma dinâmica particular quanto aos ventos, insolação e umidade relativa que afetam direta ou indiretamente na temperatura do ar, umidade e precipitação. O Clima é caracterizado como $\mathrm{Cfb}$ segundo Koppen.

Em termos regionais têm-se as marcas da influência das reativações de estruturas do embasamento associadas à atividade mesozoica que provocou Arco de Ponta Grossa e os lineamentos estruturais mais significativos na direção noroeste-sudeste como o Alinhamento São Alonzo: uma anomalia paralela ao eixo do arco. (ASSINE, 1996; PONTES, 2014).

Em relação à Geologia, a bacia se estende sobre o material do Grupo Paraná: tendo na base a Formações Furnas e Ponta Grossa, e na sequência a Formação Campo Mourão, do Grupo Itararé (MINEROPAR,2005).

A Formação Furnas é representada por rochas sedimentares, formada por arenitos finos, médios a muito grossos, feldspáticos e ou cauliníticos, quartzosos de coloração esbranquiçada, com estratificação cruzada, ocorrendo níveis conglomeráticos (ASSINE, 1999).

Acrescentando a isso, a MINEROPAR (2005) caracteriza o arenito Furnas como: Arenitos brancos, de granulação média a grossa, micáceos, feldspáticos, de matriz caulínica e estratificação cruzada com níveis conglomeráticos. Melo (2013) descreve que a coloração clara do arenito é devida à 
presença da caulinita e ilita que agem como agente cimentante dos grãos de quartzo e feldspato. Os arenitos da Formação Furnas dão sustentação ao degrau topográfico representado pela Escarpa Devoniana e compõem a unidade geológica dominante no reverso desta escarpa. com horizontes conglomeráticos basais e granodecrescência ascendente. Acima dos arenitos basais, a unidade caracteriza-se por intercalação complexa entre intervalos arenosos e diamictíticos, com tendência geral de afinamento granulométrico para o topo (MINEROPAR, 2006).
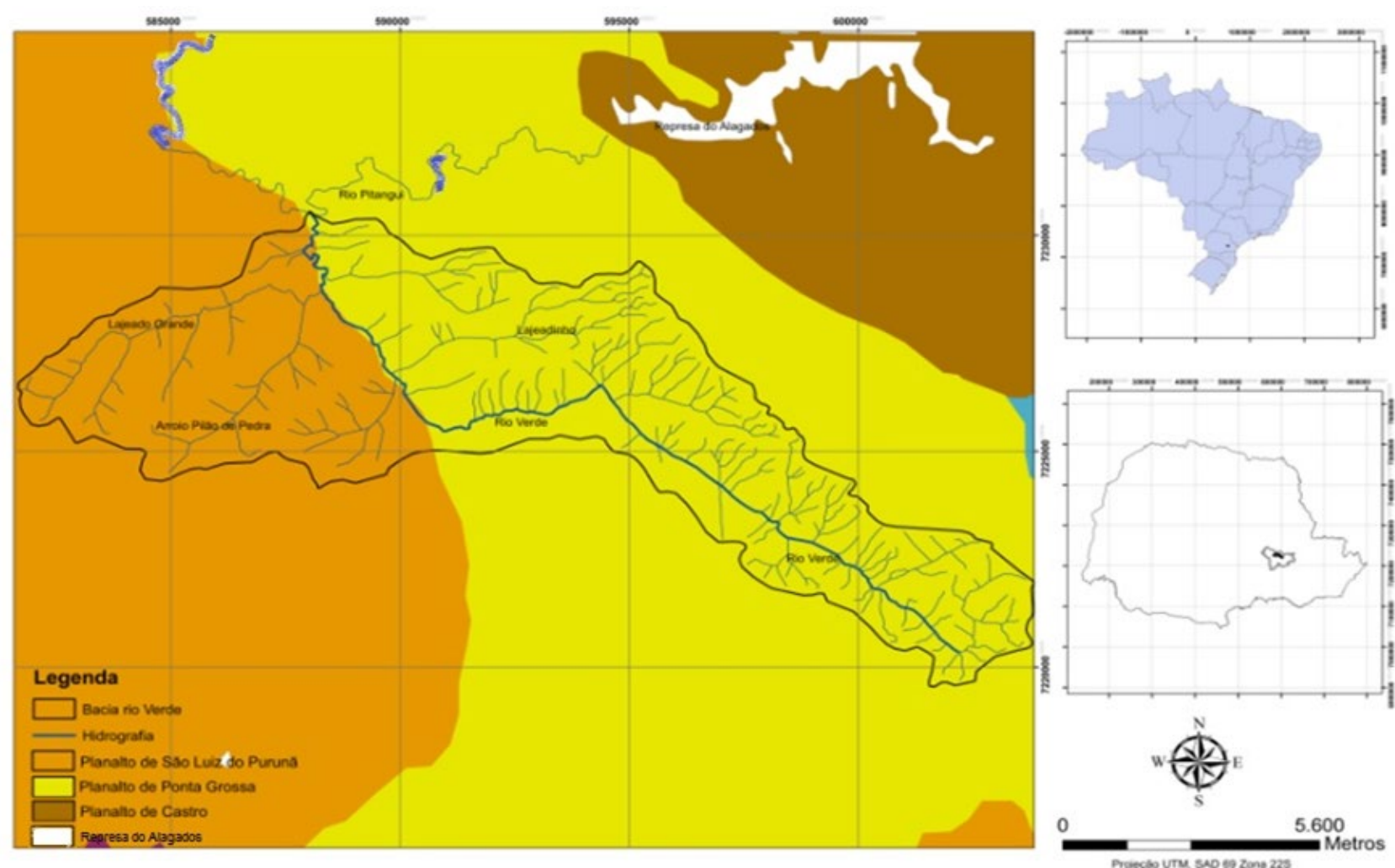

Figura 01: Localização da área de estudo.

Fonte: PMPG (2009).

A Formação Furnas constitui-se como importante área de reserva hídrica do aquífero, porém com grande risco de contaminação que aumenta com o uso de agrotóxicos e lançamento de efluentes (MELO, 2009).

A Formação Ponta Grossa é composta por folhelhos acinzentados com laminação plano-paralela. Nos níveis siltico/arenosos ocorre estratificação cruzada cavalgante e micro-hummocky. Os folhelhos laminados ricos em fóssil são sugestivos de ambiente marinho raso de plataforma, com influência da ação de tempestades (MINEROPAR, 2006).

A Formação Campo Mourão apresenta-se com arenitos desde finos a grossos, maciços com estratificação plano-paralela, cruzadas planares ou acanaladas, laminação cruzada cavalgante e eventualmente feições de deformação hidroplástica. Ocorrem na forma de corpos amalgamados de geometria tabular/lenticular ou como ciclos de base erosiva
Quanto às características topográficas apresenta altitude com variação de 400 metros e variando entre 800 e 1.000 metros sobre o nível do mar. Morfologicamente, as vertentes apresentam dissecação baixa com o predomínio de topos aplainados; terço superior e médio convexos e vales semiabertos. Os segmentos retilíneos da drenagem resultam do controle estrutural, sendo quase sempre fortemente encaixados (MINEROPAR, 2006).

As feições morfológicas dominantes têm aspectos ruiniformes, tipicamente de relevos cárstico, apresentando desabamentos quando no teto de erosões subterrâneas. (MELO et al., 2011). Estas formas e feições decorrem da fragilidade do arenito Furnas à ação da dissolução, pela presença de cimento caulinítico, sendo caracterizando como um processo de carste não-carbonático (PONTES, 2014).

Alguns rios têm seus cursos controlados por estru- 
turas de falhas, fraturas, diques, originando, inclusive, quedas d'água. Em termos geomórficos a área de estudo inclui um forte controle estrutural, que favorece a ação da erosão diferencial (BIGARELLA, 2003). Isto explica, em parte, o padrão retangular dos canais fluviais acompanhando as linhas de fraqueza estruturais e orientadas pela direção do mergulho das camadas que mantem a estratificação cruzada.

\subsection{Material e Métodos}

Para caracterizar os indicadores geomorfológicos, considerando a litoestrutura e o relevo da bacia como condicionantes do padrão dos vales, fez-se necessários dois momentos de pesquisa (Fig. 2) realizados concomitantemente.

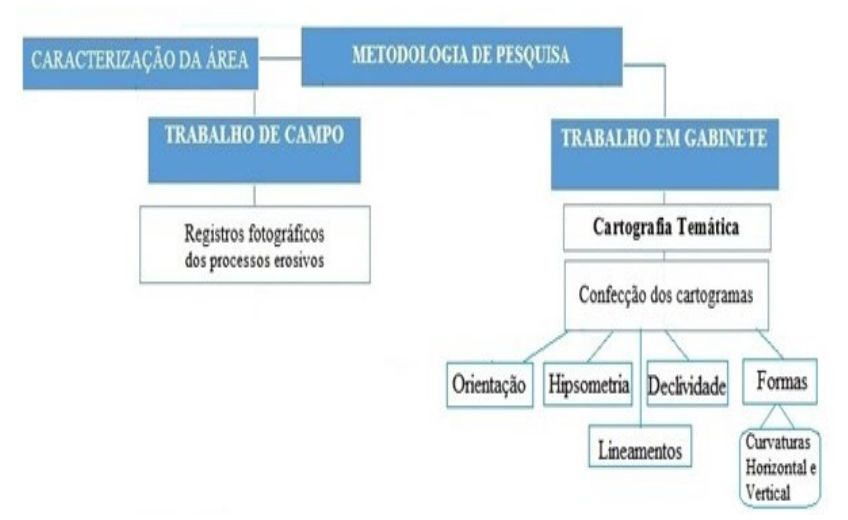

Figura 2: Fluxograma representando a operacionalização da pesquisa

Para alcançar o objetivo foi necessário a confecção de uma base cartográfica. Para a vetorização da bacia e hidrografia foram utilizadas cartas topográficas, da Diretoria de Serviço Geográfico (DSG), em escala 1:50.000. Além disso, escolheu-se a imagem de radar referente ao projeto ASTER GDEM (Advanced Spaceborne Thermal Emission and Reflection Radiometer) com resolução de 30 metros disponibilizada gratuitamente no endereço eletrônico: https://gdex. cr.usgs.gov/gdex/. Na identificação das formas do terreno foram utilizadas imagens Shuttle Radar Topography Mission (SRTM) com resolução espacial de 30 metros do Projeto Topodata (INPE). O datum de coordenadas planas foi SAD69 UTM Zone 22S (projeção da área de estudo).

Toda a pesquisa foi validada pelos trabalhos de campo, servindo para a localização e reconhecimento dos processos erosivos, dos lineamentos, do controle estrutural e registros fotográficos.

\subsubsection{Mapa de Hipsometria e Declividade}

Os dados cartográficos -curvas de nível- foram processadas no Spatial Analyst Tools do software ArcGIS 10.3.1. A hipsometria foi extraída pelo modelo digital do terreno (TIN) com sete classes variando de 1150 a 840 metros acima do nível do mar e, posteriormente, a declividade foi obtida pela inserção do TIN na ferramenta Slope, com base na Advanced Spaceborne Thermal Emission and Reflection Radiometer (ASTER). Dividiu-se o terreno em seis classes, conforme EMBRAPA (2006): 0 - $3 \%$ (plano), 3 - 8\% (suave ondulado), 8 - $20 \%$ (ondulado), 20 - $45 \%$ (forte ondulado), $45-75 \%$ (montanhoso) e $>75 \%$ (escarpado). Este indicador auxilia a visualização dos processos morfogênicos atuantes na bacia.

\subsubsection{Mapa de Orientação e Formas de vertentes}

Foram utilizados os dados geomorfométricos derivados de processamentos efetuados em imagens Shuttle Radar Topography Mission (SRTM) com resolução espacial de 30 metros do Projeto Topodata, disponíveis no website do Instituto Nacional de Pesquisas Espaciais (INPE), em diferentes planos de informação (Valeriano et al., 2008). A orientação das vertentes foi extraída pela ferramenta Aspect do aplicativo em questão.

Dentro do propósito deste artigo, utilizou-se o layer forma do terreno (FT), que representa as curvaturas horizontal e vertical associadas, quem resultam em uma imagem, contendo nove classes de formas, conforme figura 3.

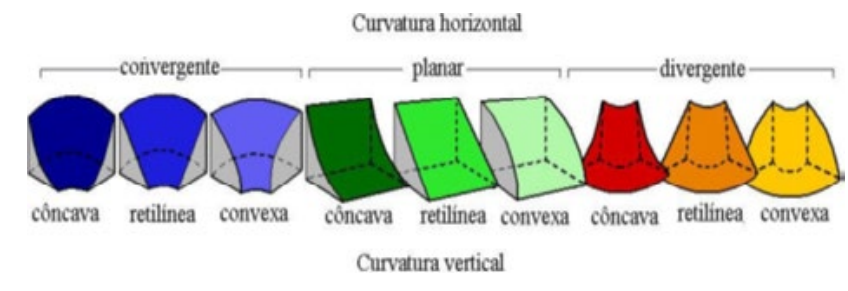

Figura 3: Subdivisões das formas do terreno (FT).

Fonte: GUASSELLI et al, 2009.

\subsubsection{Algebra de Mapas e extração dos lineamentos estruturais}

Em seguida realizou-se o cruzamento dos dados Forma do Terreno x Orientação das Vertentes, através da técnica de Álgebra de mapas, que possibilita a sobreposição de rasters e a quantificação dos dados nas respectivas classes.

O tamanho de célula utilizada foi dez metros. $\mathrm{Na}$ confecção desta etapa, os dados são inseridos na ferramenta Map Algebra do Spatial Analyst Tools. Ao final, realizou-se a reclassificação da legenda, através do método estatístico de quantis, existente no software de mapeamento. Para a definição dos limites dos intervalos de classes e o agrupamento destas, selecionaram-se as seguintes tarefas em sequência: 
properties - symbology - classified- classify- method - quantile. No item identificado pela palavra "classes" determinou-se o número de classes de nove, indicando nove formas do terreno em nove orientações distintas.

No processo de extração dos lineamentos estruturais foram utilizados os dados topográficos do TOPODATA (2008), a partir da técnica de sombreamento e realces de azimute, no software ArcGIS, com objetivo de interpretar visualmente as feições. Posteriormente, com auxilio do software Spring 5.4.2 (INPE, 2002), foi possível a interpretação dos Diagramas de Roseta, referentes à frequência e ao comprimento dos referidos lineamentos.

\section{RESULTADOS E DISCUSSÃO}

A bacia hidrográfica do Rio Verde drena uma área de $85,72 \mathrm{~km}^{2}$ e possui uma extensão de $42,384 \mathrm{~km}$, tendo suas cabeceiras posicionadas a 1115 metros acima do nível do mar localizado no reverso da cuesta da Escarpa de período Devoniano, e deságua no Rio Pitangui a 840 metros de altitude, nos limites municipais de Carambeí e Ponta Grossa, perfazendo uma amplitude altimétrica da ordem de 270 metros.

Os canais fluviais apresentam, em sua maioria, típico padrão de drenagem paralelo, reflexo do controle, neste caso, pelos lineamentos oriundos do basculamento tectônico do Arco de Ponta Grossa. Isto tornou possível a melhor compreensão da dinâmica geomorfológica da área de estudo.

Quanto às formações geológicas, a Formação Furnas apresenta a maior abrangência na área, em torno de $64 \%$, seguida de $22 \%$ da F. Ponta Grossa (sendo estas duas integrantes do Grupo Paraná) e 14\% da F. Campo Mourão (Grupo Itararé).

\subsection{Hipsometria e declividade}

A paisagem dos Campos Gerais e, em particular da bacia do rio Verde, pode ser reconhecida pela presença de feições e formas de relevo resultante da ação combinada entre fatores endógenos e exógenos (tectônicos), que passiva e ativamente ainda influenciam a evolução da paisagem. Sua topografia é caracterizada por um relevo que varia de plano a suave ondulado na bacia. Nas áreas de topos (mais plano), o processo de infiltração da água é facilitado. Já nas áreas de encosta, os processos de morfogênese são mais acentuados.

A bacia apresenta altitudes que variam entre $795 \mathrm{~m}$ a $1140 \mathrm{~m}$. Na figura 4, observa-se que o canal principal se encaixa sobre uma falha bem definida. A declividade influenciadora da velocidade do escoamento superficial ao longo das vertentes, condiciona uma maior ou menor capacidade de infiltração da água da chuva e afetando a suscetibilidade de erosão dos solos. A bacia apresenta um relevo ondulado a suavemente ondulado ou vertentes planas, com declividade variando de 0 a 20\%. As maiores declividades situam-se nas vertentes cujo canal principal encontra-se encaixado em lineamentos estruturais de orientação SE-NW, como o Arco de Ponta Grossa. Algumas vertentes foram analisadas quanto a declividade média e comprimento, conforme tabela 1.

Tabela 1: Indicadores geomorfológicos de quatro vertentes - Bacia do Rio Verde, Ponta Grossa, PR.

\begin{tabular}{|c|c|c|c|c|c|}
\hline & $\begin{array}{c}\text { Altura da } \\
\text { vertente }(m)\end{array}$ & $\begin{array}{l}\text { Comprimento } \\
(\mathrm{m})\end{array}$ & Forma & Orientaçăo & $\begin{array}{l}\text { Declividade } \\
\text { média }\end{array}$ \\
\hline $\begin{array}{l}\text { Vertente } \\
01\end{array}$ & 70 & 830 & Convexa convergente & NE & $8,43 \%$ \\
\hline $\begin{array}{l}\text { Vertente } \\
02\end{array}$ & 65 & 656 & $\begin{array}{l}\text { Convexa divergente a } \\
\text { planar }\end{array}$ & SE & $9,91 \%$ \\
\hline $\begin{array}{l}\text { Vertente } \\
03\end{array}$ & 95 & 985 & Convexa divergente & SW & $9,64 \%$ \\
\hline $\begin{array}{l}\text { Vertente } \\
04\end{array}$ & 40 & 1312 & $\begin{array}{l}\text { Convexa/Retilinea } \\
\text { divergente }\end{array}$ & SW & $3,05 \%$ \\
\hline
\end{tabular}

Os principais processos morfogênicos visualizados em vertentes características são: início de solifluxão, escoamento difuso e laminar (Figura 5.1), rastejamento (creep), sulcos (Figura 5.2) e ravinas. Estes processos, após as chuvas, vêm tornando-se cada vez mais perceptíveis, pois os solos da Formação Furnas são arenosos e quando saturam com a água tornam-se sujeitos aos movimentos de massa, citados acima.

Estes ambientes resultam em grande beleza cênica (Fig.5.3 e 5.4), em sua maioria situam-se no Parque Nacional dos Campos Gerais (PNCG), criado em 2006. Formas, como furnas, são comuns na área dos PNCG..

\subsection{Influência morfoestrutural das formas do relevo}

As formas predominantes, na bacia, são topos aplainados, vertentes convexas e vales em calha muito encaixados. A direção geral da morfologia é NW-SE, no sentido do Arco de Ponta Grossa, modelada por rochas da Formação Furnas que são favoráveis aos processos de erosão laminar ou areal. Suas características morfoestruturais refletem um relevo dissecado e com canais entalhados podendo-se perceber pela Relação de relevo (Rr), cujo valor na bacia do rio Verde é de $10,7(\mathrm{~m} / \mathrm{km})$ considerado como valor médio.

A orientação das vertentes, reflete o caminho que a água de chuva percorre, favorecendo a ocorrência de processos erosivos. Na área da bacia, a orientação do relevo é marcada no sentido NW-SW. A variável orientação das vertentes mostra um predomínio das classes Noroeste (13,96\%), Norte $(10,79 \%)$, Nordeste $(9,47 \%)$, Oeste $(11,46 \%)$, Sudoeste $(18,51 \%)$, Sul $(11,94 \%)$, Sudeste $(8,22 \%)$, Leste $(5,75 \%)$, e 9,9\% Plano. 


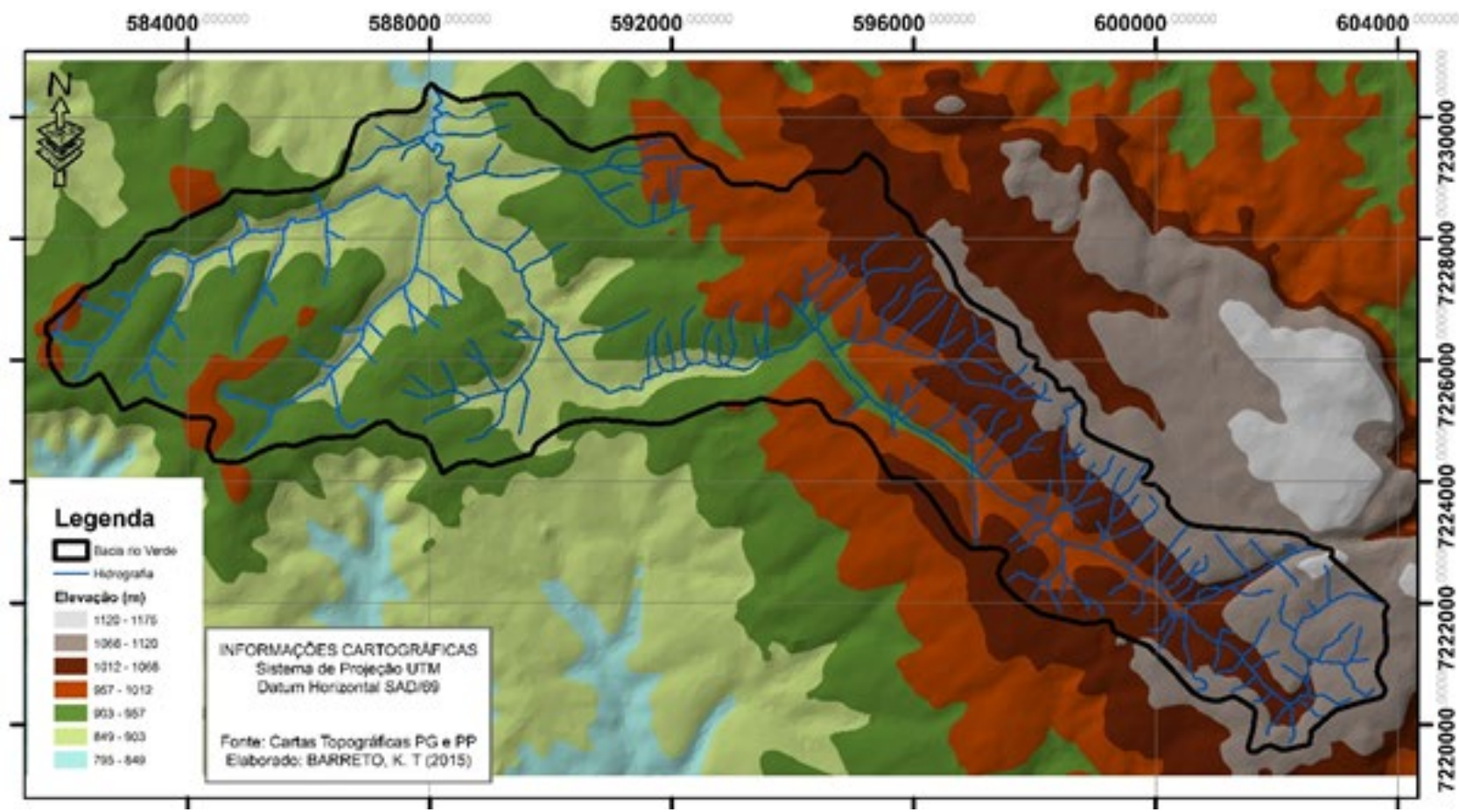

Figura 4: Cartograma de Hipsometria da bacia do rio Verde - PR.
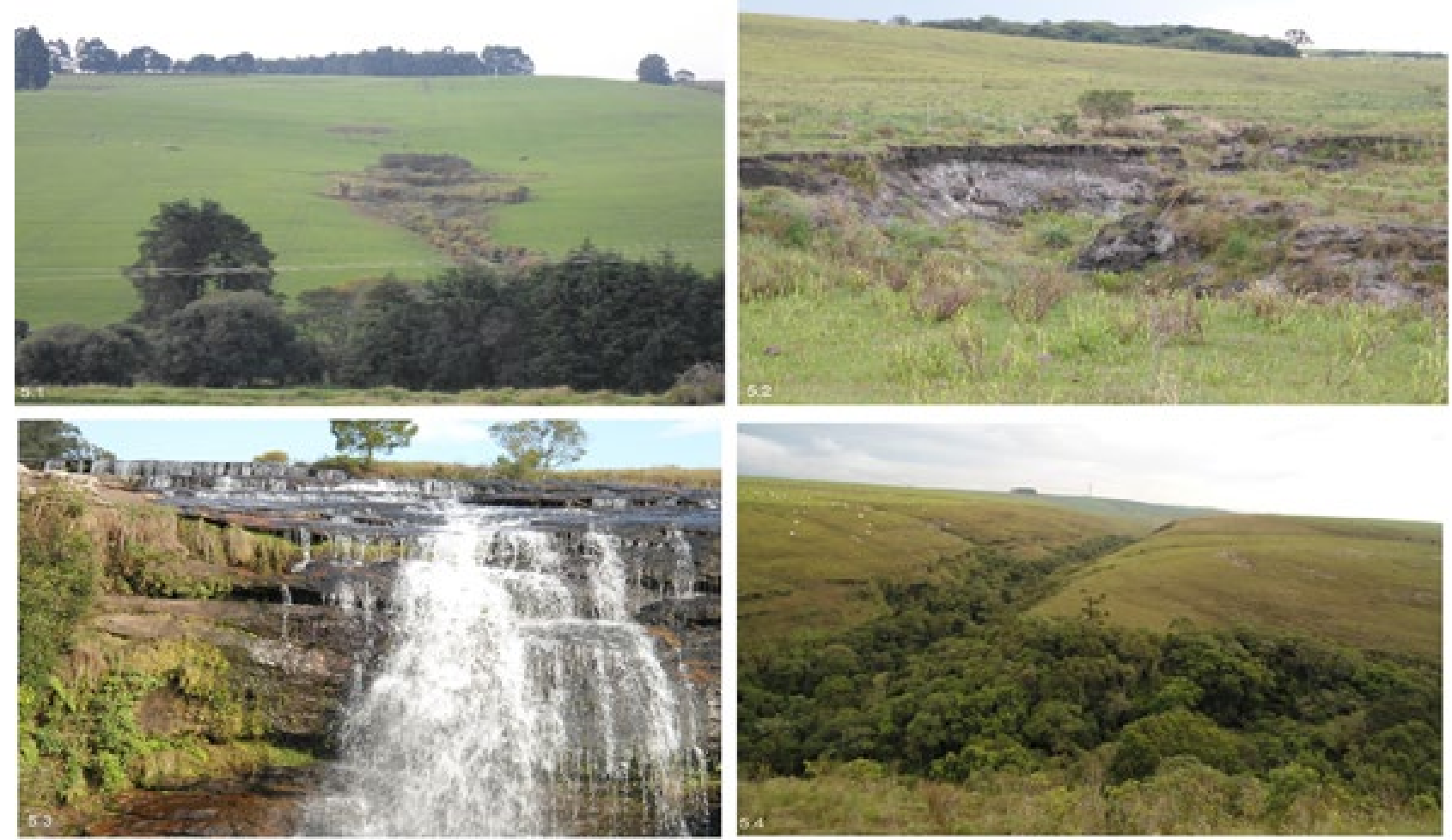

Figura 5: Exemplos de processos erosivos em vertentes da bacia (5.1 e 5.2) e belezas cênicas da área de estudo (5.3 e 5.4)

Geografia, Ensino \& Pesquisa, Vol. 21 (2017), n.2, p. 164-173

ISSN: 2236-4994 DOI: $10.5902 / 2236499424088$ 
Percebe-se dois padrões de orientação das vertentes no canal principal, onde na margem esquerda há predominância para a face $\mathrm{N}$ e suas derivações totalizando $34,22 \% \mathrm{e}$ na margem direita para a face $S$ num total de $38,67 \%$.

$\mathrm{Na}$ área de estudo, segundo Cruz (2009), o aquecimento é mais acentuado do que nas demais vertentes de orientação definida sobre os divisores de água e nos fundos de vale abertos, onde o relevo é plano, exceto das vertentes com exposição no quadrante $\mathrm{N}$ que são mais influenciadas pelas variações de temperatura, em função de que a quantidade de insolação tem relação direta com o quadrante de exposição da vertente.

As curvaturas das vertentes influenciam nos processos de migração e acúmulo de água, minerais e matéria orgânica no solo através da superfície, proporcionados pela gravidade (VALERIANO et al., 2007). Na área de estudo, as classes de forma convexa compõem $15,5 \mathrm{~km}^{2}$ da bacia correspondendo a 18,09\%. As áreas côncavas representam $17,3 \mathrm{~km}^{2}$ e 20,19\% da área. As formas retilíneas apresentam a predominância de $61,76 \%$ com $53,02 \mathrm{~km}^{2}$.

A bacia possui, em 35\% de sua área, a classe de curvatura horizontal convergente (quadro 1: classes 1,2,3) que, segundo Guasseli et al. (2009), oferece condições de forte vulnerabilidade às perdas de solo por erosão.

A classe planar somou 24\% (quadro 1: classes 4,5,6); e a classe divergente somou $41 \%$ (quadro 1: classes 7,8,9); representando riscos de moderado a baixo (GUASSELLI et al, 2009).

A classe divergente-retilínea apresenta maior abrangência, sendo mais comuns com vertentes voltadas a N-NW; em seguida, a convergente-retilínea apresenta faces para $\mathrm{N} \mathrm{e}$ SW.

Quadro 1: Quantificação das formas do terreno e sua orientação na bacia do rio Verde.

\begin{tabular}{|c|c|c|}
\hline Classe (FT) & $\begin{array}{l}\text { Area } \\
\left(\mathrm{km}^{2}\right)\end{array}$ & Area $\left(\mathrm{km}^{2}\right)$ nas respectivas orientaç̧̄es \\
\hline 1(convergente-côncava) & 12,34 & $\begin{array}{l}1,5(\mathrm{~N}) ; 1,01(\mathrm{NE}) ; \quad 0,8(\mathrm{NW}) ; 1,64(\mathrm{E}) ; \quad 2,07(\mathrm{SE}) ; 1,84(\mathrm{~S}) ; \\
1,51(\mathrm{SW}): \quad 1,05(\mathrm{~W}): \quad 0.9(\text { Plano })\end{array}$ \\
\hline 2 (convergente-retilinea) & 16,88 & $\begin{array}{l}2,99(\mathrm{~N}) ; 1,18(\mathrm{NE}) ; \quad 1,76(\mathrm{NW}) ; 1,42(\mathrm{E}) ; 2,03(\mathrm{SE}) ; 2,19(\mathrm{~S}), \\
2,21(\mathrm{SW}): 1,83(\mathrm{~W}) ; \quad 1,59 \text { (Plano) }\end{array}$ \\
\hline 3 (convergente-convexa) & 1,13 & $\begin{array}{l}0,42(\mathrm{~N}) ; 0,17(\mathrm{NE}) ; 0,16(\mathrm{NW}) ; 0,13(\mathrm{E}) ; 0,19(\mathrm{SE}) ; 0,18(\mathrm{~S}) ; \\
0,21(\mathrm{SW}) ; 0,18(\mathrm{~W}) ; 0,2 \text { (Plano) }\end{array}$ \\
\hline 4 (planar-côncava) & 2,79 & $\begin{array}{l}0,5(\mathrm{~N}) ; 0,31(\mathrm{NE}) ; 0,24(\mathrm{NW}) ; 0,41(\mathrm{E}) ; 0,56(\mathrm{SE}) ; 0,46(\mathrm{~S}): \\
0,41(\mathrm{SW}) ; 0,24(\mathrm{~W}) ; 0,31(\mathrm{Plano})\end{array}$ \\
\hline 5 (planar-rotilinea) & 14,46 & $\begin{array}{l}2,97(\mathrm{~N}): 0,95(\mathrm{NE}): 1,6(\mathrm{NW}) ; 1,13(\mathrm{E}): 1,65(\mathrm{SE}) ; 1,83(\mathrm{~S}) ; \\
1,62(\mathrm{SW}) ; 1,46(\mathrm{~W}) ; 1,51 \text { (Plano) }\end{array}$ \\
\hline 6 (planar-convexa) & 3,26 & $\begin{array}{l}0,71(\mathrm{~N}) ; 0,22(\mathrm{NE}) ; 0,34(\mathrm{NW}) ; 0,29(\mathrm{E}) ; 0,46(\mathrm{SE}) ; 0,51(\mathrm{~S}) ; \\
0.47(\mathrm{SW}) ; 0.33(\mathrm{~W}) ; 0.43 \text { (Plano) }\end{array}$ \\
\hline 7 (divergente-côncava) & 2,07 & $\begin{array}{l}0,52(\mathrm{~N}) ; 0,25(\mathrm{NE}) ; 0,2(\mathrm{NW}) ; 0,29(\mathrm{E}) ; 0,38(\mathrm{SE}) ; 0,37(\mathrm{~S}) ; \\
0.31(\mathrm{SW}): 0.19(\mathrm{~W}) ; 0.2 \text { (Plano) }\end{array}$ \\
\hline 8 (divergente-retilinea) & 21,67 & $\begin{array}{l}5,29(\mathrm{~N}) ; 1,36(\mathrm{NE}) ; 2,61(\mathrm{NW}) ; 1,53(\mathrm{E}) ; 2,02(\mathrm{SE}) ; 2,13(\mathrm{~S}) ; \\
2,27(\mathrm{SW}) ; 2,28(\mathrm{~W}) ; 2,46 \text { (Plano) }\end{array}$ \\
\hline 9 (divergente-convexa) & 11,09 & $\begin{array}{l}2,73(\mathrm{~N}) ; 0,78(\mathrm{NE}) ; 1,35(\mathrm{NW}) ; 0,83(\mathrm{E}) ; 1,13(\mathrm{SE}) ; 1,22(\mathrm{~S}) ; \\
1,12(\mathrm{SW}) ; 1,08(\mathrm{~W}) ; 1,33 \text { (Plano) }\end{array}$ \\
\hline Total & $85,7 \mathrm{~km}$ & maior área está orientada para: $N, N W$ e SE \\
\hline
\end{tabular}

Geografia, Ensino \& Pesquisa, Vol. 21 (2017), n.2, p. 164-173

ISSN: 2236-4994 DOI: 10.5902/2236499424088
Os resultados obtidos para essa bacia apresentaram a seguinte relação quanto às vertentes: verificou-se que há uma faixa entre as fácies de dissecação que são mais suscetíveis à ação erosiva, devido à transição morfológica do relevo (Escarpa Devoniana). Ressalta-se, ainda que as fácies mais baixas (próximas à foz) se comportam como zonas preferenciais de ocorrência de processos erosivos, assim como descrito em Marçal (2000).

Quanto a predominância nas classes de forma retilínea, podendo ser divergente, convergente ou planar, percebendose um menor percentual da forma convergente convexa, que se explica pela distribuição espacial dos canais fluviais. Já, a forma divergente retilínea apresenta uma maior distribuição, sendo comum a ocorrência de processos erosivos nestas áreas (já demonstrados anteriormente na Figura 5.1 e 5.2).

\subsubsection{Lineamentos estruturais}

Os lineamentos de relevo referem-se aos trechos retilíneos de drenagem, totalizando 13 lineamentos que variam de 1 a 10,3 km cada, tendo um comprimento médio de $2,7 \mathrm{~km}$ (figura 6).

Ao analisar os diagramas de rosáceas (Fig.7), verificase que, o comprimento absoluto dos lineamentos apresenta um padrão parecido com a distribuição da frequência. Percebe-se que há uma maior frequência e comprimento dos lineamentos no quadrante NE, na direção N40-70E mostrando-se importantes no contexto geológico regional. A sua presença se relaciona às estruturas do embasamento cristalino, reativadas durante as atividades de arqueamento. Fato já demonstrado por Pereira et al. (2014); Oliveira e Cassol Pinto (2015).

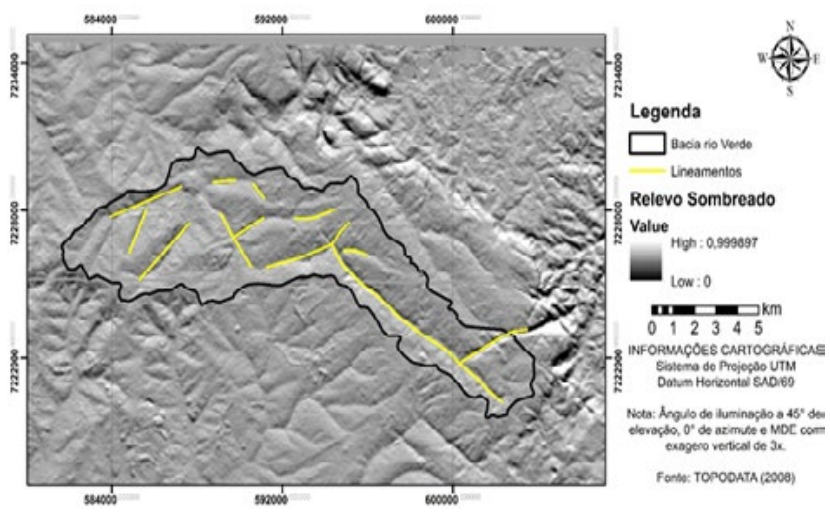

Figura 6: Principais lineamentos, em comprimento, de vales retilíneos da bacia do rio Verde - PR

Outros lineamentos estão presentes na bacia com tamanhos não tão expressivos, principalmente na direção N40-60W. Estes lineamentos com direções NW estão diretamen- 
te ligados à influência do Arco de Ponta Grossa.
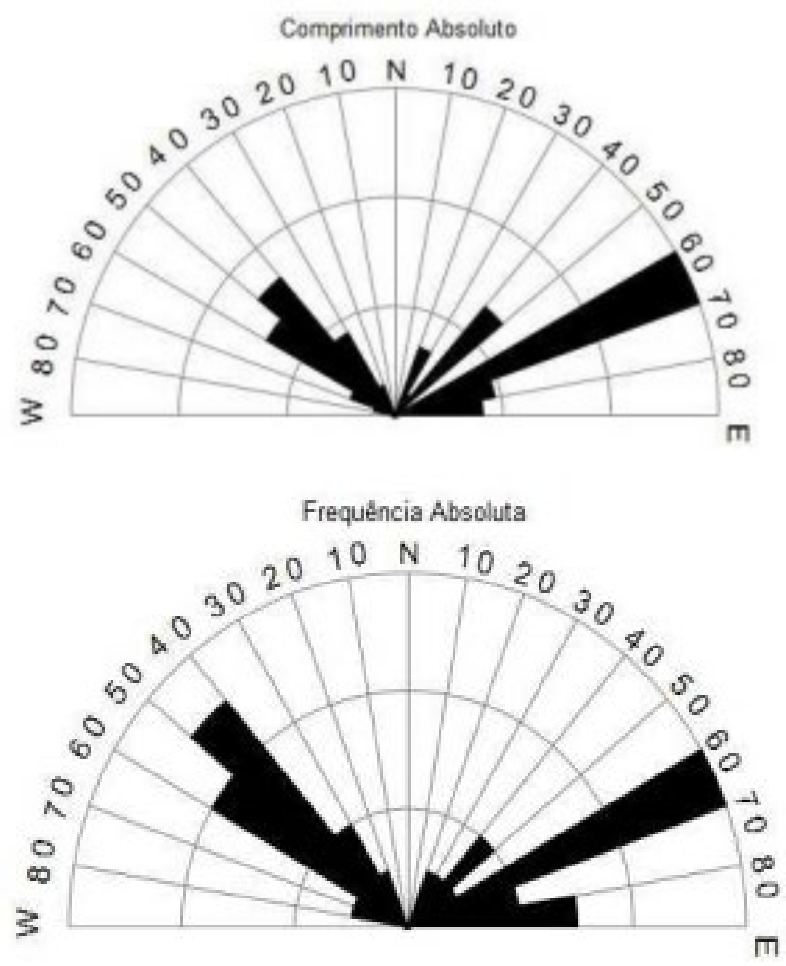

Figura 7: Diagramas de rosáceas referentes aos lineamentos da bacia do rio Verde - PR

A maioria dos lineamentos observados coincidem com a presença de linhas de fratura. Outros, no entanto, estão associados a contatos estratigráficos, normalmente com reflexos morfológicos.

\section{CONSIDERAÇÕES FINAIS}

Se o objetivo desta pesquisa foi caracterizar os indicadores geomorfológicos na bacia hidrográfica do rio Verde, pode-se afirmar que, forma, declividade e orientação da vertente, serviram como base para o entendimento dos processos erosivos morfogênico, bem como para demonstrar a influência dos eventos tectônicos e do contexto geológico ao qual se insere a referida bacia.

A bacia apresenta, no geral, um relevo dissecado com topos aplainados e vertentes suavemente onduladas, entre as quais o canal principal entalhou o vale, que se apresenta fortemente encaixado, em algumas áreas, quando percorre os lineamentos estruturais e, quando fora deles, exibe pequenas faixas de planícies de inundação.

As formas do terreno mais ocorrentes são divergente-retilínea, sendo mais comuns com vertentes voltadas a
N-NW; em seguida, a convergente-retilínea apresenta faces para N e SW com fácies de dissecação que são mais suscetíveis à ação erosiva, devido à transição morfológica do relevo (Escarpa do Devoniana).

Os lineamentos de relevo se referem aos trechos retilíneos de drenagem, totalizando 13 lineamentos que variam de 1 a 10,3 km cada, tendo um comprimento médio de 2,7 $\mathrm{km}$. Percebe-se que há uma maior frequência e comprimento dos lineamentos no quadrante NE, na direção N40-70E mostrando-se importantes no contexto geológico regional.

A Geomorfologia desta área ressalta a estreita relação de dependência entre processos/formas/declividade de vertentes com a presença de lineamentos estruturais. E ainda que, tais lineamentos, quando associados à rede hidrográfica, sejam marcados pela relação entre vertentes convexas - convergentes / divergentes- e feições fluviais de grande beleza cênica, como identificada no Capão da Onça e, mais expressivamente, em locais da bacia, situados no interior do Parque Nacional dos Campos Gerais.

Assim, vê-se como necessário aplicar e discutir os indicadores geomorfológicos de forma integrada às outras técnicas voltadas tanto para os estudos morfoestruturais e morfotectônicos, como para o planejamento dos usos do solo, rural/urbano e, em especial, ao investimento do turismo rural e aventura.

\section{REFERÊNCIAS}

ASSINE, M. L. Aspectos da estratigrafia das sequências pré-carboníferas da Bacia do Paraná no Brasil. 1996. Tese (Doutorado em Geologia Sedimentar) - Programa de Pós-Graduação em Geologia Sedimentar, USP, São Paulo - SP.

. Fácies, Icnofósseis, Paleocorrentes e sistemas deposicionais da Formação Furnas no Flanco Sudeste da Bacia do Paraná. Revista Brasileira de Geociências n. 29(3), p. 357-370, set. 1999.

BIGARELLA, J. J. Estrutura e Origem das Paisagens Tropicais e Subtropicais. Florianópolis: Editora UFSC, 2003.

CONACHER, A. J. \& DALRYMPLE, J. B. The nine unit landsurface model: an approach to pedogeomorphic research. Geoderma, London, n. 18., 1977.

CRUZ, G. C. F. Clima urbano de Ponta Grossa-PR: uma abordagem da dinâmica climática em cidade 
media subtropical brasileira. 2009. Tese (Doutorado em Geografia). Programa de Pós-Graduação em Geografia, USP, São Paulo - SP.

EMBRAPA., Empresa Brasileira de Pesquisa Agropecuária. Sistema brasileiro de classificação de solos. Rio de Janeiro, 2006.

GUASSELLI, L. A.; EVERS, H.; OLIVEIRA, M. G.; SUERTEGARAY, D. M. A. Definição de padrões de formas das vertentes relacionadas com a ocorrência de areais, através de dados geomorfométricos, em sub-bacias da Bacia Hidrográfica do Rio Ibicuí - RS In: XIV Simpósio Brasileiro de Sensoriamento Remoto, 2009, Natal. Anais... INPE, 2009.p. 3867-3874.

GUERRA, A. J. T. Geomorfologia e Meio Ambiente. Rio de Janeiro: Bertrand Brasil, $4^{\circ}$ ed., 2003.

INPE - Instituto Nacional de Pesquisa Espacial. Sistema de Processamento de Informações Georreferenciadas. SPRING - Manual do usuário. São José dos Campos - SP, 2002.

IPARDES - INSTITUTO PARANAENSE DE DESENVOLVIMENTO ECONÔMICO E SOCIAL. Relação dos municípios do estado ordenados segundo as mesorregiões e as microrregiões geográficas do IBGE - Paraná - 2012. Disponível em: < http://www. ipardes.gov.br/pdf/mapas/base_fisica/relacao_mun_micros_mesos_parana.pdf >

MAACK, R. Notas preliminares sobre clima, solos e vegetação do Estado do Paraná. Curitiba, Arquivos de Biologia e Tecnologia, v. 02, p.102-200, 1948.

Geografia física do Estado do Paraná. 3.ed. Curitiba: Imprensa Oficial, 2002.

MARÇAL, M.S. Suscetibilidade à erosão dos solos no Alto Curso da Bacia do rio Açailândia - Maranhão. 2000. Tese de Doutorado (Programa de Pós-Graduação em Geografia), UFRJ, Rio de Janeiro - RJ.

MELO, M. S. de. Aquífero Furnas - Urgência na Proteção de Mananciais Subterrâneos em Ponta Grossa, PR. In: Seminário Internacional Experiências de Agendas 21: Os desafios do nosso tempo, Ponta Grossa - PR. Anais... 2009.
MELO, M. S. de; GUIMARÃES G. B.; PONTES, H. S.; MASSUQUETO, L. L.; PIGURIM, I.; BAGATIM, H.Q.; GIANNINI, P. C. F. Carste em rochas não-carbonáticas: o exemplo dos arenitos da Formação Furnas, Campos Gerais do Paraná/ Brasil e as implicações para a região. Espeleo-Tema, v. 22, n.1, p. 79-95, set. 2011.

MELO, M. S. de. Perfurações de cupins e geomorfogênese em arenitos paleozoicos da região dos Campos Gerais do Paraná. Quaternary and Environmental Geosciences; n.04, p. 25-33, 2013.

MINEROPAR - Minerais do Paraná S.A. Atlas geológico e geomorfológico do estado do Paraná: escala base 1:250.000, Curitiba: MINEROPAR/UFPR, 2006.

O'LEARY, D. W.; FRIEDMAN, J. D.; POHN, H. A. Lineament, linear, lineation: some proposed new standards for oldterms. GSA Bulletin, v. 87, p. 1463-1469, 1976.

OLIVEIRA, K. A.; CASSOL PINTO, M. L. Correlação morfoestrutural da rede de drenagem na bacia do Alto curso do rio Pitangui - Paraná. Revista Geoingá, v. 7, n. 1, p. 25-41, 2015.

PEREIRA, D. C..; OLIVEIRA FILHO, R.; CARNEIRO, M. M.; LIMA, D.; CASSOL PINTO, M. L. Lineamentos estruturais da borda oriental da Bacia Sedimentar do Paraná: um estudo entre Carambeí e Ponta Grossa, nos Campos Gerais do Paraná. Revista Geonorte, v.10, n.6, p. 167-172, 2014.

PONTES, H. S. Espacialização de feições cársticas da Formação Furnas: ferramenta para Gestão do Território no Município de Ponta Grossa (PR). 2014. Dissertação (Mestrado em Gestão do Território). Programa de Pós-Graduação em Geografia, UEPG, Ponta Grossa - PR.

TOPODATA - Banco de dados Geomorfométricos do Brasil. Disponível em: http://www.dpi.inpe.br/topodata/

VALERIANO, M. M. Topodata: guia para utilização de dados geomorfológicos locais. INPE: Coordenação de Ensino, Documentação e Programas Especiais, São José dos Campos, SP, 2008. 


\section{Correspondência das autoras:}

Karla Thais Barreto

e-mail: karlatbarreto@gmail.com

\section{Maria Ligia Cassol Pinto}

e-mail: ligialhc@gmail.com

Artigo recebido em: 20/09/2016

Revisado pelo autor em: 19/02/2017

Aceito para publicação em: 14/03/2017 